Forthcoming at the Journal of the Academy of Marketing Science

\title{
How and when weather boosts consumer product valuation
}

\author{
Tobias Schlager \\ Emanuel de Bellis \\ JoAndrea Hoegg
}

Author Note

Tobias Schlager is assistant professor of marketing at the Faculty of Business and Economics, Université de Lausanne, UNIL-Dorigny, Bâtiment Anthropole 3054, CH-1015 Lausanne, Switzerland (tobias.schlager@unil.ch). Emanuel de Bellis is assistant professor of marketing at the Institute for Customer Insight, University of St. Gallen, Bahnhofstrasse 8, CH-9000 St. Gallen, Switzerland (emanuel.debellis@ unisg.ch). JoAndrea Hoegg is associate professor of marketing and behavioural science at the Sauder School of Business, University of British Columbia, BC, V6T 1Z2, Canada (joey.hoegg@ sauder.ubc.ca). 


\begin{abstract}
Weather is an ever-present force in consumers' daily lives, yet marketing lacks a comprehensive understanding of how and when it affects consumers and businesses. The current research investigates the effect of weather, a ubiquitous environmental cue, on consumers' valuation of products. A large-scale field study and four experiments demonstrate that weather affects product valuation but only under particular conditions. In line with a process account drawing on mental simulation of product use, product valuation increases only if (1) the product is associated (vs. not associated) with a given weather state, as the match of product and weather facilitates mental simulation, and (2) the product is perceived as attractive (vs. unattractive), as mental simulation highlights both positive and negative product characteristics. We test three weather statessunshine, snowfall, and rain — and find that our effects emerge for sunshine and snowfall but not for rain, as the latter does not enhance mental simulation. The findings advance literature on the effects of environmental cues and mental simulation and guide firms on how to increase consumers' valuation of products by weather-related measures.
\end{abstract}

\title{
Keywords
}

Weather, product valuation, mental simulation, environmental cues, online auctions 


\section{Introduction}

Firms increasingly exploit weather to improve their business. Coca Cola was among the pioneers in dynamically adjusting the prices for its products sold in vending machines, selling at higher prices on hotter days (King and Narayandas 2000). More recently, a range of businesses from ski areas and zoos to Major League Baseball teams have started to take weather into account when pricing their offerings (Nicas 2015). In response to the increasing recognition of weather effects and initial attempts to capitalize on them, firms such as Weather Co. (theweathercompany.com) and Weatherunlocked (weatherunlocked.com) have emerged to advise businesses on how to boost their sales based on weather.

Research in marketing, psychology, and economics demonstrates that weather can affect individuals and their consumption behavior (Buchheim and Kolaska 2016; Busse et al. 2015; Hong and Sun 2012; Murray et al. 2010; Zwebner, Lee, and Goldenberg 2013). Prior work has focused either on general weather effects (Buchheim and Kolaska 2016; Busse et al. 2015) or on the effects of sunshine as the most salient weather state (Cunningham 1979; Hirshleifer and Shumway 2003). Despite several empirical studies, the psychological processes driving weatherrelated effects are largely unexplored. It has been assumed that specific weather states such as sunshine affect consumption behavior by influencing consumers' mood-but only a few studies showed empirical evidence for this effect (Murray et al. 2010). Because of the limited research on the underlying processes of weather effects, it is largely unknown under which circumstances weather affects product valuation.

Our key proposition is that weather affects the valuation of products only when consumers associate the product with a given weather state because these environmental cues spur mental simulation of product use, which in turn increases consumers' product valuation (Elder and Krishna 2012; Lehmann et al. 2007; Thompson, Hamilton, and Petrova 2009). We argue that 
such a mental simulation account offers a more comprehensive understanding of weather-related effects than current accounts drawing on mood or product need (Buchheim and Kolaska 2016; Busse et al. 2015; Murray et al. 2010). We also propose that a mental simulation account leads to more specific predictions. Specifically, the effect of weather on product valuation should unfold only for (1) products associated (vs. not associated) with a given weather state, as the match between product and weather (i.e., when a product or its usage context is associated with a specific weather state) should facilitate mental simulation, and (2) products that are attractive (vs. unattractive), as mental simulation highlights the positive (vs. negative) usage consequences of the product. In addition, we demonstrate that the mental simulation account applies mainly to sunshine and snowfall, whereas a need account is better able to explain a greater valuation of products that match rain.

A combination of a large-scale field study (involving 3.6 million observations) and four experiments supports our hypotheses while offering several theoretical and practical implications. First, we reveal that the dominant process underlying the effects of sunshine and snowfall is mental simulation. Second, we provide novel insights into the downstream consequences of weather by demonstrating that weather affects product valuation only under specific conditions. Third, our research contributes to the literature on mental simulation by identifying unobtrusive environmental cues as antecedents of this mental process. Finally, our findings allow businesses to better understand and predict the occurrence, magnitude, and direction of the effect of weather on product valuation, which permits them to improve their pricing and product marketing strategies.

\section{Theoretical background and hypotheses}

\section{The distinct effects of weather}


Research in marketing, psychology, and economics found that weather can substantially influence consumer behavior. For example, consumers are more likely to purchase convertibles in times of warm and sunny weather while opting for a four-wheel drive vehicle right after a snow storm (Busse et al. 2015). A field study on sales of outdoor movie tickets showed that consumers purchase tickets depending on the weather at the time of the purchase, despite its irrelevance to the experience of visiting the theater in the future (Buchheim and Kolaska 2016). Besides work on general weather effects, a large bulk of research has focused on the effects of one specific weather state-sunshine. Sunshine has been shown to increase individuals' helping and tipping behavior (Cunningham 1979; Keller et al. 2005), even when consumers were simply informed that the current or forecasted weather was pleasant (Rind 1996; Rind and Strohmetz 2001). Sunshine has also been shown to correlate with increased stock prices (Hirshleifer and Shumway 2003; Saunders 1993), and to impact the effectiveness of mobile phone advertisements, with higher and faster purchase responses to promotions during sunny (vs. cloudy and rainy) weather (Li et al. 2015). Finally, sunshine has been found to increase consumer spending (Murray et al. 2010).

In short, weather has been related to various behavioral changes, with sunshine positively affecting properties such as stocks, promotions, and everyday products. Based on these findings, one would not only expect that weather can affect valuation of products, but also that in particular that sunshine would do so uniformly.

\section{The underlying mechanism of weather-related effects}

Early work suggested that weather affects store sales either due to physically preventing people from visiting the store or because of its "psychological effects" (Steele 1951). More recent work can be grouped into two large categories: a mood account (which is specific to sunshine) and a need account. One line of argumentation is that sunshine, the most salient weather state, enhances 
consumers' mood, which in turn affects product valuation in line with other well-established effects of mood on consumer decision making (Cohen, Pham, and Andrade 2008). Although a number of studies explicitly or implicitly draw on this mood account (Cunningham 1979;

Hirshleifer and Shumway 2003; Li et al. 2015; Rind 1996; Rind and Strohmetz 2001), most reviewed work did not directly test this assumption. In fact, studies directly investigating the role of mood have reported mixed results. Murray et al. (2010) showed that negative mood mediates the positive effect of sunshine on sales but found this effect only for one product category (i.e., tea) and only at lower temperatures. Lee et al. (2014) showed that sunshine reduces individual productivity as it distracts individuals but did not find any effects of mood. Thus, the empirical evidence for a mood account is limited.

A second line of argumentation is that weather merely elicits the need for products typically consumed during that particular weather state. For example, hot summers are associated with gains to the beer and wine industries (Agnew and Palutikof 1999). Related to a need account is projection bias, which may lead consumers to overvalue products associated with a current weather state by predicting "a greater number of warm-weather states in the future when the current weather is warm relative to when the current weather is cold" (Busse et al. 2015, p. 402). In a similar vein, Buchheim and Kolaska (2016) attributed their findings to psychological effects (i.e., salience effects, projection biases, and extrapolative expectations) but also acknowledged "some uncertainty as to which specific psychological mechanism affects the customers' intertemporal decision making” (p. 21). Importantly, a need account (in contrast to a mood account) requires that a product matches a specific weather state; projection bias can be considered a subcategory of a need account that includes a heightened product need for future (instead of present) events. 
Building on this prior work, we propose a novel account by which weather affects product valuation. Specifically, we argue that the effect of weather on product valuation operates mainly via mental simulation, which is defined as the "cognitive construction of hypothetical scenarios" (Escalas 2004, p. 37). We argue that the effect of weather on mental simulation unfolds primarily when the product matches the context. A central determinant of mental simulation is the extent to which individuals perceive the context of an activity to be simulated in detail (Escalas 2004). Individuals are better able to mentally simulate an activity when environmental cues match that activity, just as these cues may impede individuals' imagination of a situation when they are at odds with a given activity (Riccio, Richardson, and Ebner 1984; Smith and Vela 2001). Consistent with this notion, we argue that weather stimulates mental simulation only when the focal activity — or product related to that activity—matches a weather state. For example, we predict that sunshine enhances consumers' mental simulation of product use if the focal product is associated with sunshine (e.g., an outdoor product), as this would constitute a match between product and context. However, if the focal product is not associated with sunshine (e.g., an indoor product), sunshine should not enhance mental simulation. Once mental simulation is triggered, it has significant consequences for consumers' subsequent behavior. Mental simulation supports turning thoughts into action (Taylor and Schneider 1989) and enhances consumers' attitudes toward products (Escalas 2004; Hildebrand, Häubl, and Herrmann 2014; Nielsen, Escalas, and Hoeffler 2018; Zhao et al. 2011). Imagining a product allows consumers to connect to that product (Elder and Krishna 2012), which subsequently enhances its valuation (Heyman, Orhun, and Ariely 2004; Pierce, Kostova, and Dirks 2003). Accordingly, mental simulation of product use should increase consumer product valuation.

Imagine the example of a consumer who is considering buying a pair of sunglasses, a product that is typically associated with sunshine. Our theorizing predicts that sunshine facilitates 
the consumer's mental simulation of wearing the sunglasses and, as a result, increases the valuation of the sunglasses. By contrast, the same consumer's valuation should not increase for reading glasses because sunshine would not enhance the mental simulation of wearing reading glasses. Note that this prediction differs from an explanation that draws on mood, which would suggest that sunshine increases product valuation independent of the extent to which the product is associated with sunshine (Cohen, Pham, and Andrade 2008).

\section{The moderating role of product attractiveness}

Thus far, we have argued that weather increases valuation of products associated with a particular weather state. However, one could come to the same conclusion by arguing that such a match merely evokes the need for a product that is typically consumed on days with a particular weather state (Agnew and Palutikof 1999), consistent with the predictions of projection bias (Bucheim and Kolaska 2016; Busse et al. 2015). In particular, one might assume that weather serves as a mere reminder of the need for a product associated with that weather state, just as one might assume that the future utility of a product depends on the match of weather and a product. If this were the case, weather should increase the valuation of any product associated with that weather state - a prediction that is at odds with a mental simulation account.

Mentally simulating a product highlights its features and usage. If a product is of poor quality or is unattractive, mental simulation of product use (e.g., imagining wearing an unattractive shirt in public) will render these aspects more salient (Elder and Krishna 2012; Sanna 2000), potentially decreasing consumer product valuation. This line of argumentation is known as the availability-valence hypothesis (Petrova and Cialdini 2005). Notably, this prediction differs from what a need account (including projection bias) would suggest. Whereas both accounts predict that weather increases the valuation of products associated with that weather state, a mental simulation account predicts that unattractive products are valued less if the product is 
associated with a specific weather state. By contrast, a need account would suggest that matching the product with a particular weather state increases product valuation for any product associated with that weather state, independent of its attractiveness.

Returning to the sunglasses example, sunshine should increase mental simulation irrespective of the sunglasses' attractiveness. However, if the sunglasses are perceived as unattractive, the increased mental simulation should decrease product valuation since imagining wearing the sunglasses increases the salience of the undesirable features and usage consequences.

\section{Summary and hypotheses}

The central proposition of this research is that weather is a key determinant of product valuation but only for products that are associated with a particular weather state (e.g., sunshine for sunrelated products). Given that weather is a cue that facilitates consumers' imagination of the usage situation, it should stimulate mental simulation of using such products. This, in turn, should increase product valuation. More formally,

H1: A weather state increases the valuation of products associated with that state but fails to increase the valuation of products not associated with that state.

H2: Mental simulation of product use mediates the positive effect of a weather state on the valuation of products associated with that state.

Mental simulation should decrease valuation when the product under consideration is perceived to be unattractive. In this case, weather increases consumers' ability to imagine the product's negative characteristics, which should lead to a negative effect of mental simulation on valuation. More formally,

H3: The effect of mental simulation of product use on product valuation is positive for attractive products but negative for unattractive products.

Fig. 1 depicts the conceptual model of the effect of weather on product valuation. 
--- Insert Fig. 1 about here ---

\section{Overview of studies}

We test the effects of weather on product valuation with a combination of large-scale field studies and tightly controlled experiments. Employing a dataset of an online auction platform involving 3.6 million observations, Study 1 reveals that matching a sun- or snow-related product (but not a rain-related product) with the respective weather state leads to an increased bidding price (H1), with a first indication for mental simulation being key for the effects $(\mathrm{H} 2)$. A follow-up experiment on the specificity of the effects confirms that mental simulation is the primary driver for products associated with sun or snow, whereas product need drives the effect for products associated with rain. Study 2 uses a multi-factorial experimental design to show that the effect of weather on product valuation occurs only for products associated with a specific weather state (H1), and reveals that mental simulation of product use mediates this effect $(\mathrm{H} 2)$. Study 3 manipulates weather via weather forecasts and shows that the mere prospect of a productmatching weather state can spur consumers' mental simulation and product valuation. Study 3 also addresses alternative explanations such as mood and product need. Study 4 demonstrates that a match between weather and the product is not universally beneficial, as mental simulation decreases product valuation for unattractive products $(\mathrm{H} 3)$, thereby providing experimental evidence against a need account. Study 5 orthogonally manipulates weather and consumers' mood by means of advertisements and shows that the effect of weather on product valuation occurs via mental simulation independently of mood.

We conducted all studies in auction settings using either a self-reported measure of product valuation or consumers' bidding price for a product as a natural and accurate measure of product valuation (Chan, Kadiyali, and Park 2007). The auction context is also relevant given that companies such as eBay have access to consumers' location, and thus can easily implement 
weather-related measures. To increase the external validity of our results, our empirical package includes studies that investigate real-world auction behavior with consequential choices. The web appendix includes replication studies of all experiments except for Study 3, which involved a specific event.

\section{Study 1}

Study 1 aims at providing preliminary insights into two central hypotheses of this paper $(\mathrm{H} 1, \mathrm{H} 2)$ in a real setting. We obtained and analyzed a large dataset from an online auction platform. The dataset included actual purchases from a broad variety of product categories that differ in the extent to which they are associated with different weather states.

Whereas we have conceptualized mental simulation as a mediator (H2), in this study we provide support for our proposed process through moderation (Spencer, Zanna, and Fong 2005) by testing mental simulation as an exogenous moderator. We use a naturally occurring measure in auction settings as proxy for mental simulation: the number of product images. We expect that the number of images will positively moderate the interaction of weather and the extent to which a product is associated with that weather state.

\section{Procedure}

Data collection We obtained data from a large Swiss online auction platform of all products sold over a one-year period (January to December 2015). Information available from the dataset included the product and product category, the exact time of each bid, demographics of buyers, and the number of articles sold by sellers. We focused on bids that were made (1) during daylight hours and (2) with desktop, laptop, or tablet devices to ensure that product images were displayed 
appropriately. This procedure resulted in a total of 3,624,642 auctions by 202,572 unique customers $\left(M_{\text {age }}=49.31, S D_{\text {age }}=13.34 ; 27 \%\right.$ female $)$.

Measures To control for potential confounding factors, we used several control variables, namely month, weekday, time of day of the auction, daylight at the specific bid location (identified by the customer's zip code and matched on a daily basis), customers' gender, age, and their location (i.e., zip code), the number of articles sold per seller, and the condition of the article (new vs. used). The focal independent variable was the weather state at the time of the bid (sun, rain, snow, other). We received this information from wunderground.com and matched it with the exact time stamp of each bid. The focal dependent variable was a customer's final bidding price in each auction the customer participated in $(M=107.80$ Swiss Francs, $S D=367.27$ Swiss Francs). All predictors were mean-centered and the bidding price was log-transformed. Pretests To assess products' association with each weather state, we conducted a pretest $(\mathrm{N}=$ $185 ; M_{\text {age }}=35.00, S D_{\text {age }}=10.60 ; 41 \%$ female $)$ asking respondents from Amazon Mechanical Turk (MTurk) to rate each of the 100 available product categories for their association with one single weather state (i.e., sun, rain, snow): "Please judge the following product categories:" "Product category" [product category] has..." $1=$ "nothing to do with [weather state]" to 7 = "a lot to do with [weather state]". Next, we used the ten product categories that scored highest for each of the weather states and coded them as either sun, rain, or snow-related. In cases in which a product category was rated among the highest for more than one weather state (e.g., jackets were associated with both rain and snow), the product category was assigned to the weather state with the higher mean.

To obtain a measure for customers' mental simulation of product use, we used the number of images that were shown in the auction of each article. Specifically, some auctions displayed only few images of the product in their product descriptions, while others displayed multiple 
images (e.g., showing the product from different angles and how it is used). Using the number of images as proxy for mental simulation was inspired by prior work (Elder and Krishna 2012) and supported by a second pretest with 199 participants from MTurk $\left(M_{\mathrm{age}}=36.19, S D_{\mathrm{age}}=12.48\right.$; $52 \%$ female) entailing two conditions: Participants in the image condition received the full product description of standard sunglasses with an image of the sunglasses, whereas those in the no image condition received the same product description without an image. Then, all participants completed a measure of mental simulation by two items ("How well could you imagine the product?" and "How well could you imagine using the product?" measured on 7point scales from $1=$ "imagining was difficult" to $7=$ "imagining was easy"; $r=.61$; Elder and Krishna 2012; Escalas 2004). Mental simulation was significantly higher in the image (vs. no image $)$ condition $\left(M_{\text {image }}=5.32, M_{\text {no_image }}=4.30, t(197)=5.57, p<.001, d=.79\right)$, demonstrating the effectiveness of images at enhancing mental simulation. Note that whereas number of images captures mental simulation only indirectly, it allowed us to assess mental simulation for each of the 3.6 million auctions and even to distinguish between the same products (when the number of images differs across auctions for the same products).

\section{Results}

Bidding price As some customers participated in multiple auctions, we used linear mixed effects models to analyze the auction data, accounting for zip codes using a random intercept. We estimated three distinct models (see Table 1). In model 1, the baseline model, we used merely the control variables and weather as predictors of bidding price. Results showed that only sunshine had a positive effect on the amount customers bid for products $(b=.01, S E=.002, t=6.02, p<$ $.001)$, while snowfall had no effect $(b=-.01, S E=.01, t=-1.28, p=.20)$, and rain had a negative effect $(b=-.01, S E=.003, t=-1.79, p=.07)$. In model 2, we added the match as predictor of bidding price as well as an interaction with weather states to test whether different weather states 
affect the amount customers bid for a product depending on whether the product matched each of the weather states $(\mathrm{H} 1)$. This interaction was significant for all weather states $\left(b_{\text {match } \times \text { sunshine }}=.20\right.$, $S E=.01, t=32.40, p<.001 ; b_{\text {match } \times \text { snowfall }}=.08, S E=.02, t=3.30, p<.001 ; b_{\text {match } \times \text { rain }}=.23, S E=$ $.03, t=6.80, p<.001)$. This provides preliminary evidence that products associated with each of the weather states yield a higher bidding price when that weather state is present.

--- Insert Table 1 about here ---

In model 3, we added the extent to which a product can be mentally simulated and specified three-way interactions of weather, a product category's match with the particular weather state, and the number of images displayed for a specific product. Number of images positively moderated the interaction for sunshine $(b=.02, S E=.01, t=3.24, p=.001)$ and snowfall $(b=$ $.08, S E=.02, t=3.22, p=.001)$ but showed a negative effect for rain $(b=-.11, S E=.04, t=-$ $2.46, p=.01)$. Model 3 was the most explanatory and, at the same time, most parsimonious model. The results demonstrate that a match between product, weather, and mental simulation yielded higher bidding prices only for sunshine and snow but not for rain. This provides initial evidence that those two weather states drive mental simulation but that this mental simulation might even decrease bidding prices for rain.

\section{Discussion}

Study 1 provided initial evidence for our two central hypotheses (H1, H2) across a broad variety of products that differed in (1) the extent to which they are associated with a weather state and (2) the number of product images uploaded to the online auction platform. We found significant positive effects for sunshine and snowfall but surprisingly a negative effect for rain. We speculate that this is caused by consumers' association with each weather state. Specifically, sunshine and snowfall are typically associated with enjoyable activities, and many sun- and snow-related 
products (e.g., sunglasses, beach towels, ski jackets, snowshoes) tend to enable those activities. By contrast, rain is associated with less enjoyable activities, and products commonly associated with rain are typically products that are used to protect against the weather state rather than enable an activity (e.g., rain ponchos).

Follow-up study To extend the findings from Study 1 we conducted a scenario-based experiment (for full details, see Web Appendix A). We administered a 3 (weather state: sunshine vs. rain vs. snowfall $) \times 2$ (product match: yes vs. no) between-subjects design $\left(\mathrm{N}=404 ; M_{\text {age }}=\right.$ $35.96, S D_{\text {age }}=10.77 ; 50 \%$ female $)$. We manipulated weather state by asking participants to imagine that outside there was sunshine, rain, or snowfall (see Web Appendix B). Participants were then randomly assigned to one of six different products (i.e., beach towel, sandals, rain boots, poncho, hat, winter jacket). If the product corresponded to the condition (e.g., sunshine and beach towel / sandals), we coded a match with the weather state (coded as "1"; otherwise "0"). We then assessed participants' degree of mental simulation, perceived need for the product, and positive and negative mood states in order to test the psychological processes spurred by imagining the weather states and a fitting product.

A mediation analysis (Process Model $4, N_{\text {bootstraps }}=10,000$; Hayes 2012) with match as independent variable, mental simulation, need, positive and negative affect as parallel mediators, product valuation as dependent variable, and the evaluated product as a control variable revealed that the indirect effect of match on product valuation via mental simulation was significant for the sunshine and the snowfall conditions but not for the rain condition $\left(b_{\text {sunshine }}=.41, S E=.21, \mathrm{CI}_{95}=\right.$ $\left.[.03 ; .88] ; b_{\text {rain }}=.13, S E=.12, \mathrm{CI}_{95}=[-.10 ; .40] ; b_{\text {snowfall }}=.49, S E=.22, \mathrm{CI}_{95}=[-.13 ; .99]\right)$. In all conditions the indirect effect via need was significant $\left(b_{\text {sunshine }}=1.01, S E=.30, \mathrm{CI}_{95}=[.47 ; 1.63]\right.$; $\left.b_{\text {rain }}=1.10, S E=.22, \mathrm{CI}_{95}=[.70 ; 1.59] ; b_{\text {snowfall }}=.39, S E=.19, \mathrm{CI}_{95}=[.07 ; .84]\right)$, while the indirect effects via positive affect $\left(b_{\text {sunshine }}=.02, S E=.11, \mathrm{CI}_{95}=[-.21 ; .26] ; b_{\text {rain }}=.03, S E=.04\right.$, 
$\left.\mathrm{CI}_{95}=[-.02 ; .15] ; b_{\text {snow }}=.06, S E=.06, \mathrm{CI}_{95}=[-.05 ; .20]\right)$ and negative affect were non-significant $\left(b_{\text {sunshine }}=.01, S E=.03, \mathrm{CI}_{95}=[-.02 ; .12] ; b_{\text {rain }}=-.01, S E=.04, \mathrm{CI} 95=[-.12 ; 05] ; b_{\text {snow }}=.02, S E=\right.$ $\left..03, \mathrm{CI}_{95}=[-.02 ; .12]\right)$. The largest part of the effect for sunshine and snowfall was mediated by mental simulation, whereas the effect for rain was explained by an increased need for the product (for rain-related products mental simulation did not drive product valuation). This is consistent with Study 1 and prior work suggesting that mental simulation is more relevant when evaluating positively described alternatives (Elder and Krishna 2012), while negatively described alternatives are evaluated in terms of their importance and are thus more closely related to a need account (Keller and McGill 1994).

Study 1 and its follow-up provide initial evidence for the influential role of mental simulation when weather matches a given product. The subsequent studies were designed to offer conclusive evidence. Moreover, all studies focus on sunshine given it is the most prevalent weather state (on average, US cities have 105 days with sunshine and only 14 days with snow; see Web Appendix C).

\section{Study 2}

Study 2 was designed with two objectives. First, we aimed to provide evidence that the effect of weather on product valuation is specific to products associated with these weather states by experimentally manipulating this match (H1). Second, the study examined the underlying process by directly measuring mental simulation of product use and testing whether it qualifies as a mediator of the effect of sunshine on product valuation $(\mathrm{H} 2)$.

\section{Pretest}

We conducted a pretest with 48 American participants $\left(M_{\text {age }}=38.35, S D_{\text {age }}=13.34 ; 44 \%\right.$ female $)$ from MTurk to test our manipulation of association with sunshine. The focal product in this study 
was a shirt. While the visual representation of the outdoor and indoor shirt was identical, the description varied slightly between conditions. The shirt was described as a "stylish t-shirt, perfect for outdoor (indoor) activities" and was accompanied by several attributes (e.g., "high wearing comfort while walking (sitting)"; see Web Appendix D for stimuli). Participants rated the shirt's association with sunshine on a one-item scale ("Please rate the shirt according to its association with sunshine", 1 = "nothing to do with sunshine" to 7 = "a lot to do with sunshine"). The pretest was successful in that the outdoor (vs. indoor) shirt was rated to be significantly more associated with sunshine $\left(M_{\text {outdoor }}=4.04, M_{\text {indoor }}=2.68 ; t(46)=2.97, p=.004, d=.86\right)$.

\section{Procedure}

For the main study, we administered a 2 (sunshine: yes vs. no) $\times 2$ (association with sunshine: yes vs. no) between-subjects design. Association with sunshine was manipulated by describing the shirt as primarily for outdoor versus indoor use. One hundred and fifty-four American participants $\left(M_{\mathrm{age}}=36.65, S D_{\mathrm{age}}=11.54 ; 53 \%\right.$ female $)$ were recruited from MTurk for monetary compensation. As part of a series of items, participants were screened for completing the study (1) in a room with windows, (2) during daylight, and (3) at a place that was neither too hot nor too cold to go outside. These criteria were used to ensure that participants knew about and were exposed to the current weather, and that they could imagine going outside, which is key to our mental simulation account. We applied these criteria across all online experiments that measured weather as independent variable.

The experiment consisted of two parts. In the first part, participants were introduced to the study and received a personal login to an external website (see Web Appendix E for detailed procedure). They were told that the login was necessary to access the second part of the study, in which they would bid for a product, a procedure intended to increase the realism of the online auction experience. Next, they were redirected to an external website, which was the mock-up 
online auction platform where they were prompted to enter their personal login information. Subsequently, participants were randomly assigned to bid either for the outdoor or indoor shirt. Participants were led to believe that they were bidding against another, randomly assigned MTurk user. To make participants' choices consequential, they were endowed with $\$ 1.00$ before starting the auction. The auction consisted of multiple bidding rounds in which participants had to decide whether to raise their bid by increments of $\$ .05$ (by clicking "bid now") or to keep the remaining money and close the auction (by clicking "stop bidding"). The auction platform indicated the current highest bidding price as well as the amount required to make the highest bid at any point of the auction (see Web Appendix E). The auction closed when participants declined to bid any higher or when they reached a bidding price of $\$ 1$ (the platform was programmed such that the "other user" did not surpass \$1). Participants completed the study by indicating the current weather ( $1=$ "sunny", $0=$ "not sunny") and giving demographic information.

Measures We measured product valuation by the amount participants bid for the shirt $(M=\$ .45$, $S D=\$ .33, \min =\$ 0, \max =\$ 1)$. Before bidding on the product, participants completed the same measure of mental simulation as in the follow-up study of Study $1(r=.54)$. Finally, we asked consumers to indicate the current outside temperature in Fahrenheit $(M=69.98, S D=8.99$, min $=$ $52, \max =90)$.

\section{Results}

Bidding price A two-way ANOVA on bidding price revealed no main effects of sunshine $(F(1$, $\left.150)=1.36, p=.24, \eta_{\mathrm{p}}{ }^{2}=.01\right)$ and product use $\left(F(1,150)=.14, p=.71, \eta_{\mathrm{p}}{ }^{2}=.001\right)$ but did reveal a significant interaction of sunshine and product use $\left(F(1,150)=4.79, p=.03, \eta_{\mathrm{p}}^{2}=.03\right)$. Consistent with H1, planned contrasts showed that the bidding price for the outdoor shirt was significantly higher in the sunshine (vs. no sunshine) condition $\left(M_{\text {sunshine }}=\$ .53, M_{\text {no_sunshine }}=\right.$ $\$ .35 ; p=.02)$. For the indoor shirt, we found no significant difference between the sunshine and 
no sunshine condition $\left(M_{\text {sunshine }}=\$ .41, M_{\text {no_sunshine }}=\$ .46 ; p=.48\right.$; see Fig. 2$)$. Controlling for temperature changed neither the direction nor the significance of the effect. Table 2 summarizes the results of all experimental studies.

--- Insert Table 2 about here ---

--- Insert Fig. 2 about here ---

Mental simulation Exploring the proposed mediator of mental simulation, the effects of product use $\left(F(1,150)=1.02, p=.31, \eta_{\mathrm{p}}{ }^{2}=.02\right)$ and sunshine were non-significant $(F(1,150)=2.39, p=$ $\left..12, \eta_{\mathrm{p}}^{2}=.01\right)$ but the interaction of both factors was marginally significant $(F(1,150)=3.30, p=$ $.07, \eta_{\mathrm{p}}^{2}=.02$ ). Planned contrasts showed that mental simulation of the outdoor shirt was significantly greater in the sunshine $($ vs. no sunshine $)$ condition $\left(M_{\text {sunshine }}=6.57, M_{\text {no_sunshine }}=\right.$ $6.05 ; p=.02)$, while there was no such effect for the indoor shirt $\left(M_{\text {sunshine }}=6.16, M_{\text {no_sunshine }}=\right.$ $6.21 ; p=.82)$.

Moderated mediation To examine the psychological process underlying the effect of sunshine on bidding price, we used a moderated mediation analysis (Process Model $7, N_{\text {bootstraps }}=10,000$ ) with mental simulation as mediator and product use (outdoor vs. indoor) as moderator. The indirect effect of sunshine on bidding price via mental simulation was significant for the outdoor shirt $\left(b=5.03, S E=2.71, \mathrm{CI}_{95}=[.90 ; 11.87]\right)$ but not significant for the indoor shirt $(b=-1.47$, $\left.S E=2.24, \mathrm{CI}_{95}=[-6.30 ; 2.58]\right)$. The moderated mediation index was significant $(b=-6.49, S E=$ $\left.3.70, \mathrm{CI}_{95}=[-15.27 ;-.54]\right)$, indicating that the effect of sunshine on product valuation emerged for outdoor products only.

\section{Discussion}

Study 2 used a multi-factorial experimental design to show that a product's association with a weather state determines whether that weather state positively affects product valuation $(\mathrm{H} 1)$. 
This study also provided insights into the psychological process underlying the effect by demonstrating that mental simulation mediates the effect of sunshine on product valuation $(\mathrm{H} 2)$. A replication study that did not measure the mediator before the dependent variable led to consistent results (see Web Appendix F).

\section{Study 3}

Study 3 was designed to examine whether the mere prospect of a specific weather state could affect product valuation. If the prospect of a weather state suffices to elicit the hypothesized effects (H1), companies could directly draw on our effects and influence product valuation by, for instance, selectively providing consumers with weather forecasts. In addition, this study tests the robustness of the mental simulation account by more directly examining two alternative explanations (i.e., mood and product need).

\section{Procedure}

We administered a 2 (prospect of sunshine: yes vs. no) $\times 2$ (actual sunshine: yes vs. no) betweensubjects design. Two hundred and nine American participants $\left(M_{\mathrm{age}}=35.54, S D_{\mathrm{age}}=11.22 ; 55 \%\right.$ female) were recruited from MTurk. We used the same online auction platform as in Study 2 and conducted the study three days before Mother's Day. This allowed us to present participants with a Mother's Day special ostensibly offered by the online auction platform. The focal product of this study was a bouquet of flowers. As this product may not be perceived as strongly associated with the focal weather state of this study (i.e., sunshine), we emphasized the importance of sunshine in the product description (e.g., "only when the sun shines on the flowers will they fully unfold their splendid appearance"). The product presentation was accompanied by a locationspecific weather forecast for that day. Participants were asked to enter their zip code to make the weather forecast more authentic before being randomly assigned to one of two conditions. In the 
no-prospect-of-sunshine condition, participants received a forecast showing that on Mother's Day (and until two days after that) the sun would not be shining. In the prospect-of-sunshine condition, the forecast predicted sunshine for all three days (see Web Appendix G for stimuli).

Measures We measured actual sunshine as in the previous study. In contrast to the previous study, we used a non-consequential measure for bidding price (i.e., we did not endow participants with money) to test whether requiring MTurk users to bid actual money may have impacted the results of Study 2 (e.g., by making them more sensitive to price-related questions). Moreover, we used a sealed-bid auction mechanism (i.e., participants only bid once) to simplify the process. We measured bidding price by a slider question asking: "How much would you be willing to bid for this product" $(M=\$ 26.16, S D=\$ 16.14, \min =\$ 1, \max =\$ 100)$. We measured mental simulation as in Study $2(r=.79)$, consumers' positive mood by the 10 -item PANAS scale (Watson, Clark, and Tellegen 1988; $\alpha=.93$ ), and consumers' product need by a 3-item scale ("I can use this product", "Thinking about the upcoming weeks, I need the product", "I really need the product", measured on 7-point Likert scales; $\alpha=.87$ ). Temperature was measured as in the previous study $(M=65.58, S D=12.33, \min =10, \max =90)$.

\section{Results}

Bidding price A two-way ANOVA revealed no main effect of actual sunshine $(F(1,205)=2.49$, $\left.p=.12, \eta_{\mathrm{p}}^{2}=.01\right)$ or the prospect of sunshine $\left(F(1,205)=1.48, p=.23, \eta_{\mathrm{p}}{ }^{2}=.01\right)$ on bidding price; however, the interaction of both factors was significant $\left(F(1,205)=4.03, p=.04, \eta_{\mathrm{p}}^{2}=\right.$ .02). Planned contrasts indicated that the prospect of sunshine increased bidding price only when the sun was not shining $\left(M_{\text {sun_prospect }}=\$ 28.55, M_{\text {no_sun_prospect }}=\$ 19.39 ; p=.02\right)$, whereas the prospect of sunshine had no significant effect on bidding price when the sun was already shining $\left(M_{\text {sun_prospect }}=\$ 27.18, M_{\text {no_sun_prospect }}=\$ 27.52 ; p=.90\right)$. In other words, the prospect of sunshine 
increased product valuation by replacing the effect of actual sunshine. Controlling for temperature changed neither the direction nor the significance of the effect.

Mental simulation A similar pattern emerged for consumers' mental simulation. Sunshine significantly increased mental simulation $\left(F(1,205)=4.73, p=.04, \eta_{\mathrm{p}}{ }^{2}=.02\right)$ while no significant main effect was generated by the prospect of sunshine $\left(F(1,205)=.24, p=.62, \eta_{\mathrm{p}}^{2}=\right.$ $.001)$ Importantly, there was a significant interaction of both factors $(F(1,205)=6.40, p=.01$, $\left.\eta_{\mathrm{p}}{ }^{2}=.03\right)$. Planned contrasts showed that the prospect of sunshine increased mental simulation only when the sun was not $\operatorname{shining}\left(M_{\text {sun_prospect }}=6.10, M_{\text {no_sun_prospect }}=5.44 ; p=.02\right)$, whereas the prospect of sunshine had no effect on mental simulation when the sun was shining $\left(M_{\text {sun_prospect }}=\right.$ $\left.6.01, M_{\text {no_sun_prospect }}=6.20 ; p=.31\right)$.

Alternative accounts We also examined the effect of actual sunshine on measures of alternative process accounts. Consistent with prior work (Agnew and Palutikof 1999), actual sunshine had a positive effect on consumers' product need $\left(F(1,205)=4.03, p=.05, \eta_{\mathrm{p}}{ }^{2}=.02\right)$ but neither the prospect of sunshine $\left(F(1,205)=.58, p=.45, \eta_{\mathrm{p}}^{2}=.003\right)$ nor the interaction of both factors significantly affected product need $\left(F(1,205)=.04, p=.84, \eta_{\mathrm{p}}^{2}<.001 ; M_{\text {sunshine,sun_prospect }}=4.83\right.$, $\left.M_{\text {sunshine,no_sun_prospect }}=4.68, M_{\text {no_sunshine,sun_prospect }}=4.39, M_{\text {no_sunshine,no_sun_prospect }}=4.13\right)$. Regarding mood, there were no main effects of actual sunshine $\left(F(1,205)=.20, p=.66, \eta_{\mathrm{p}}{ }^{2}=.001\right)$ or the prospect of sunshine $\left(F(1,205)=.01, p=.93, \eta_{\mathrm{p}}^{2}<.001\right)$; however, there was a significant interaction of both factors $\left(F(1,205)=4.99, p=.03, \eta_{\mathrm{p}}^{2}=.02 ; M_{\text {sunshine,sun_prospect }}=2.84\right.$, $\left.M_{\text {sunshine,no_sun_prospect }}=3.03, M_{\text {no_sunshine,sun_prospect }}=3.11, M_{\text {no_sunshine,no_sun_prospect }}=2.67\right)$. In line with prior work (Rind and Strohmetz 2001), these results suggest that the prospect of sunshine can make up for the lack of actual sunshine in terms of mood.

Moderated mediation We conducted a moderated mediation model (Process Model 7, $N_{\text {bootstraps }}$ $=10,000$ ) with the prospect of sunshine (sunshine vs. no sunshine) as the independent variable, 
mental simulation, product need, and positive mood as mediators, bidding price as the dependent variable, and actual sunshine as the moderator of the effect of the prospect of sunshine on the mediators. We suspected that the prospect of sunshine would increase mental simulation when no actual sunshine was present, compensating for the lack of actual sunshine. The indirect effect of the prospect of sunshine on bidding price via mental simulation was significant when no actual sunshine was present $\left(b=1.43, S E=1.12, \mathrm{CI}_{95}=[.02 ; 4.30]\right)$, whereas the same effect was nonsignificant with actual sunshine $\left(b=-.42, S E=.46, \mathrm{CI}_{95}=[-1.93 ; .15]\right)$. Notably, without actual sunshine, the indirect effect via positive mood was significant $\left(b=1.22, S E=.82, \mathrm{CI}_{95}=[.01\right.$; 3.17]), whereas the indirect effect via product need was non-significant $\left(b=.10, S E=.40, \mathrm{CI}_{95}=\right.$ $[-.37 ; 1.45])$. These two indirect effects were non-significant with actual sunshine (positive mood: $b=-.52, S E=.55, \mathrm{CI}_{95}=[-2.00 ; .33]$; product need: $\left.b=.06, S E=.28, \mathrm{CI}_{95}=[-.28 ; 1.04]\right)$. The moderated mediation index was significant for both mental simulation and positive mood but not for product need (mental simulation: $b=-1.84, S E=1.27, \mathrm{CI}_{95}=[-5.58 ;-.14]$; positive mood: $b=$ $-1.75, S E=1.10, \mathrm{CI}_{95}=[-4.66 ;-.21]$; product need: $\left.b=-.04, S E=.50, \mathrm{CI}_{95}=[-1.89 ; .71]\right)$. This suggests that along with our mental simulation effect, the prospect of sunshine increased participants' positive mood when actual sunshine was not present, which increased their bidding price.

\section{Discussion}

This study demonstrated that the prospect of a specific weather state manipulated by weather forecasts can have similar effects to actually being exposed to that weather state; that is, the mere expectation of a weather state can make up for the lack of actual weather. This is an important finding for marketing practice. For instance, firms that sell products associated with a specific weather state can selectively highlight weather forecasts to their customers (e.g., on their website or app), which should enhance the valuation of their products. 
Study 3 also investigated two alternative accounts for the observed effects: product need and mood. Whereas mood was found to operate as a second mediator besides mental simulation (Murray et al. 2010), product need could not account for the effects of weather on product valuation (Ülkümen and Thomas 2013). Importantly, even when controlling for both alternative accounts, the effect of mental simulation remained significant.

The process evidence thus far suggests that mental simulation and mood play similar roles in the effect of weather on product valuation. It is worth noting, however, that mood may be idiosyncratic to our manipulation of weather (i.e., sunshine). Importantly, a mood account predicts universal benefits for all products, which a mental simulation account does not predict. The next study examines a moderator that enables us to distinguish between mood and mental simulation effects.

\section{Study 4}

The main objective of Study 4 was to demonstrate the moderating role of product attractiveness in the effect of mental simulation on product valuation. A mental simulation account predicts that sunshine would decrease product valuation for unattractive products, as the enhanced mental simulation would further highlight the product's undesirable characteristics (H3). By contrast, a mood account would predict that sunshine should increase the valuation of both attractive and unattractive products.

\section{Procedure and pretest}

Pretest The focal product in this study was a pair of sunglasses. To provide a selection of sunglasses of varying attractiveness, we first conducted a pretest with 50 participants $\left(M_{\text {age }}=\right.$ $35.78, S D_{\text {age }}=10.58 ; 42 \%$ female) from MTurk. Participants were shown, in random order, 24 pairs of sunglasses that are available on Amazon. Participants rated each pair of sunglasses based 
on their visual attractiveness ( $1=$ "I don't like these sunglasses" to 7 = "I really like these sunglasses"; $M=3.43, S D=1.93$ ). A linear mixed effects model nested in participants showed that participants rated the three sunglasses coded as attractive significantly more positively than the three sunglasses coded as less attractive $(b=2.07, S E=.16, t=13.09, p<.001$, $S D_{\text {random_intercept }}=.60$; see Web Appendix $\mathrm{H}$ for stimuli).

Main study For the main study, we administered a 2 (sunshine: yes vs. no) $\times 2$ (product attractiveness: high vs. low) between-subjects design and recruited 349 American participants $\left(M_{\text {age }}=32.95, S D_{\text {age }}=7.24 ; 41 \%\right.$ female $)$ from MTurk. The procedure mirrored that of Study 3. First, consumers were introduced to the product category and responded to a measure of need for that category. Participants were then randomly assigned to one of three pairs of sunglasses that varied in attractiveness (per the pretest), using the three pairs that were rated most attractive for the high product attractiveness conditions $(M=4.55, S D=1.71)$ and the three pairs that were rated least attractive for the low product attractiveness conditions $(M=2.48, S D=1.67)$. For all attractive sunglasses, product attractiveness was coded as " 1 " ("0" otherwise). After introducing the pair of sunglasses, we asked participants to describe their thoughts when imagining wearing the sunglasses.

Measures To assess mental simulation we instructed two independent coders to evaluate the extent to which consumers" thoughts were reflecting mental simulation $(0=$ "none", $1=$ "little", or 2 = "intense"). The instructions for the coding read: "Please rate each thought according to the extent of mental simulation of product use, which is defined as the cognitive construction of hypothetical scenarios that include the usage of the product." We measured bidding price $(M=$ $\$ 11.32, S D=\$ 7.74, \min =\$ 0, \max =\$ 25)$, sunshine (60\% sunny), temperature $(M=71.74, S D=$ 18.01, $\min =10, \max =90)$, and product need $(\alpha=.95)$ as in Study 3 . This measure served as dependent variable. In addition to bidding price, we used a self-reported measure for product 
valuation to assess the robustness of the bidding price as measure for valuation ("The product is": "attractive vs. unattractive", "good vs. bad", "pleasurable vs. unpleasurable", measured on 7point semantic differentials; $\alpha=.93$; Fisher 1974). The results for the self-reported measure of product valuation are consistent with the results on bidding price and are available upon request from the authors. Finally, we used the PANAS scale to assess participants' positive $(\alpha=.92)$ and negative mood $(\alpha=.95)$.

\section{Results}

Bidding price We employed a two-way ANOVA to analyze the effects of sunshine on bidding price for attractive versus unattractive products. The results showed a marginally significant main effect of sunshine $\left(F(1,345)=3.01, p=.08, \eta_{\mathrm{p}}^{2}=.01\right)$ and a significant main effect of product attractiveness $\left(F(1,345)=14.57, p<.001, \eta_{\mathrm{p}}^{2}=.04\right)$. Importantly, and in line with $\mathrm{H} 3$, we found a significant interaction of both factors $\left(F(1,345)=4.32, p=.04, \eta_{\mathrm{p}}{ }^{2}=.01\right)$. Planned contrasts confirmed that sunshine had a significant and positive effect for the high product attractiveness condition $\left(M_{\text {sunshine }}=\$ 14.13, M_{\text {no_sunshine }}=\$ 10.99 ; p=.007\right)$ but no significant positive effect for the low product attractiveness condition $\left(M_{\text {sunshine }}=\$ 9.66, M_{\text {no_sunshine }}=\$ 9.94 ; p=.81\right)$. Controlling for temperature changed neither the direction nor the significance of the effects. Mental simulation A two-way ANOVA on the coded measure of mental simulation revealed a significant effect of sunshine $\left(F(1,345)=5.13, p=.04, \eta_{\mathrm{p}}{ }^{2}=.02\right)$ but neither a significant effect of product attractiveness $\left(F(1,345)=.28, p=.59, \eta_{\mathrm{p}}{ }^{2}=.001\right)$, nor a significant interaction of the two factors $\left(F(1,345)=.12, p=.73, \eta_{\mathrm{p}}^{2}<.001 ; M_{\text {sunshine,attractive }}=1.29, M_{\text {no_sunshine,attractive }}=1.08\right.$, $\left.M_{\text {sunshine,unattractive }}=1.31, M_{\text {no_sunshine,unattractive }}=1.16\right)$. In line with our conceptual model, we did not find a significant interaction as product attractiveness moderates the path from mental simulation to bidding price (and not the path from sunshine to mental simulation). 
Moderated mediation To examine the underlying process, we used a moderated mediation analysis (Process Model 14, $N_{\text {bootstraps }}=10,000$ ) with sunshine (yes vs. no) as independent variable, mental simulation as mediator, and product attractiveness (high vs. low) as moderator of the path from mental simulation to bidding price. The specific type of sunglasses (of the three in each of the conditions) served as control. Based on H3, we expected that low (vs. high) product attractiveness negatively moderated the effect of mental simulation on product valuation. The indirect effect of sunshine on bidding price was positive and significant for the high product attractiveness condition $\left(b=.26, S E=.20, \mathrm{CI}_{95}=[.001 ; .85]\right)$, while the indirect effect was negative and significant for the low product attractiveness condition $(b=-.36, S E=.22, \mathrm{CI} 95=[-$ $.98 ;-.05])$. The moderated mediation index was significant $\left(b=.64, S E=.36, \mathrm{CI}_{95}=[.12 ; 1.57)\right.$. Fig. 3 illustrates that the effect of mental simulation on product valuation is attenuated for unattractive products.

--- Insert Fig. 3 about here ---

Mediation with alternative accounts We estimated the same moderated mediation with positive mood, negative mood, and product need as additional mediators. The indirect effect of sunshine on bidding price via mental simulation was positive and significant for the high product attractiveness condition $\left(b=.27, S E=.19, \mathrm{CI}_{95}=[.01 ; .86]\right)$ but negative and marginally significant for the low product attractiveness condition $\left(b=-.21, S E=.17, \mathrm{CI}_{95}=[-.70 ; .01]\right)$. The moderated mediation index remained significant $(b=.47, S E=.29, \mathrm{CI} 95=[.06 ; 1.28])$. The effect of sunshine on bidding price was also mediated by positive mood for the high $(b=.55, S E=.30$, $\left.\mathrm{CI}_{95}=[.10 ; 1.32]\right)$ and low product attractiveness conditions $\left(b=.84, \mathrm{SE}=.32, \mathrm{CI}_{95}=[.33\right.$; 1.56]). Negative mood neither mediated the effect of sunshine in the high $\left(b=-.07, S E=.14, \mathrm{CI}_{95}\right.$ $=[-.53 ; .09])$ nor the low product attractiveness condition $\left(b=-.14, S E=.12, \mathrm{CI}_{95}=[-.51 ; .01]\right)$. 
Similarly, product need neither mediated the effect of sunshine in the high $\left(b=.32, S E=.23, \mathrm{CI}_{95}\right.$ $=[-.01 ; .91])$ nor the low product attractiveness condition $\left(b=-.02, S E=.13, \mathrm{CI}_{95}=[-.001 ; .18]\right)$. Importantly, none of these alternative mediators produced a significant moderated mediation index.

\section{Discussion}

Study 4 showed that product attractiveness moderated the effect of mental simulation on product valuation such that mental simulation increased the valuation of attractive products but decreased the valuation of unattractive products. Thus, this finding corroborates a mental simulation account and makes an exclusively mood-driven account less likely, as the latter would predict positive effects of mental simulation regardless of product attractiveness. This study's findings similarly speak against a need account (and thus against projection bias; Buchheim and Kolaska 2016), as they show that product need and mental simulation have differential consequences (Ülkümen and Thomas 2013). If weather was acting as a reminder that a consumer needed a particular product, valuation for that product should increase regardless of whether it was aesthetically attractive or not. In addition to addressing alternative explanations, this study demonstrated that mental simulation does not universally increase product valuation. To ensure that this effect was not due to the measure of mental simulation, we replicated this study using a self-reported measure of mental simulation and found that the effect was attenuated (see Web Appendix I).

A drawback of this study is that our pretest on product attractiveness asked for the products' visual attractiveness. This measure is positively related to our dependent variable, which was also reflected in the strong positive effect of the high attractiveness conditions. In addition, one could argue that product attractiveness would increase mental simulation. Whereas we did not find such an effect in this study, prior work has discussed the possibility that mental 
simulation might be more relevant for objects with positive characteristics (Elder and Krishna 2012; Keller and McGill 1994). The final study aimed to experimentally disentangle the effects of mental simulation from those of mood.

\section{Study 5}

To orthogonally manipulate mental simulation and mood we designed advertisements by which the weather state (i.e., sunshine)—despite stimulating mental simulation — enhances or reduces consumers' mood. Specifically, we created ads that linked the weather state to positive or negative outcomes (Andrade and Cohen 2007). By using an ad to manipulate weather, this study also provides implications for businesses that wish to increase product valuation through marketing communications.

\section{Procedure}

We administered a 2 (ad image: sunshine vs. clouds) $\times 2$ (marketing tactics: regular appeal vs. fear appeal) between-subjects design. The focal product was a bottle of sunscreen ("Nivea Sun Protect \& Moisture; SPF 50"), which was presented as an online ad. A total of 330 American participants $\left(M_{\mathrm{age}}=38.45, S D_{\mathrm{age}}=11.88 ; 49 \%\right.$ female $)$ were recruited from MTurk. After initial questions on their attitudes toward specific brands, participants were redirected to the same online auction platform used in the previous studies. In so doing, they were randomly assigned to one of four different versions of the sunscreen ad. In the sunshine condition, we used an ad that showed a sunny beach as background and thus a subtle manipulation of sunshine that alludes to the product's typical usage situation, thereby stimulating mental simulation. In the clouds condition, the ad showed a beach with clouds as background, which corresponds to a less typical usage situation of sunscreen and thus should not increase mental simulation. In the regular appeal condition, the slogan read "Sun is happiness. Sun is love. Enjoy the sun!", whereas in the fear 
appeal condition, the slogan read "Sun means danger. Sun causes skin cancer. Avoid the sun!" (see Web Appendix J for stimuli). All participants were exposed to the manipulation with the instruction to "look carefully at the ad," before being forwarded to the measures of mental simulation, mood, and product valuation, as well as weather- and study-related questions (e.g., "the ad was realistic" on a 7-point Likert scale).

Measures We measured consumers' product valuation $(\alpha=.89)$, positive $\operatorname{mood}(\alpha=.91)$, and negative mood $(\alpha=.94)$ as in Study 4. The measurement of mental simulation $(r=.85)$ followed the procedure used in Studies 2 and 3. Finally, we measured actual sunshine (76\% sunny) and temperature $(M=76.52, S D=12.68, \min =20, \max =104)$ as in the previous studies.

\section{Results}

Product valuation To analyze the effect of the two manipulations on product valuation, we used a two-way ANCOVA that controlled for current weather, temperature, and ad realism (all effects remained significant without these control variables). Results showed that ad image significantly increased product valuation $\left(F(1,323)=6.97, p=.009, \eta_{\mathrm{p}}{ }^{2}=.02\right)$, implying that sunshine increased product valuation of the advertised sun-related product (H1). In addition, we found a significant effect of marketing tactics on product valuation $\left(F(1,323)=45.74, p<.001, \eta_{\mathrm{p}}{ }^{2}=\right.$ $.12)$ and no interaction of the two factors $\left(F(1,323)=.02, p=.90, \eta_{\mathrm{p}}^{2}<.001 ; M_{\text {sunshine_regular }}=\right.$ $\left.5.65, M_{\text {sunshine_fear }}=4.77, M_{\text {cloud__regular }}=5.34, M_{\text {cloud__fear }}=4.43\right)$.

Mental simulation and mood Regarding mental simulation, we found significant effects of ad image $\left(F(1,325)=7.89, p=.005, \eta_{\mathrm{p}}^{2}=.02\right)$ and marketing tactics $(F(1,325)=8.34, p=.004$, $\left.\eta_{\mathrm{p}}{ }^{2}=.03\right)$ on mental simulation but no significant interaction of the two factors $(F(1,325)<.001$, $\left.p>.99, \eta_{\mathrm{p}}^{2}<.001\right)$. Regarding negative mood, we found that only marketing tactics $(F(1,325)=$ $\left.28.17, p<.001, \eta_{\mathrm{p}}{ }^{2}=.08\right)$ but neither ad image $\left(F(1,325)=2.45, p=.12, \eta_{\mathrm{p}}{ }^{2}=.01\right)$ nor the interaction of both factors $\left(F(1,325)=1.95, p=.16, \eta_{\mathrm{p}}^{2}=.01\right)$ significantly predicted negative 
mood. Similar effects were found for positive mood: Only marketing tactics $(F(1,325)=6.99, p$ $\left.=.009, \eta_{\mathrm{p}}{ }^{2}=.02\right)$ but neither ad image $\left(F(1,325)=.48, p=.49, \eta_{\mathrm{p}}{ }^{2}=.001\right)$ nor the interaction of both factors $\left(F(1,325)=.18, p=.67, \eta_{\mathrm{p}}{ }^{2}=.001\right)$ significantly predicted positive mood.

Mediation To examine the effect of the two manipulations in more detail, we estimated two mediation models (Process Model 4, $\left.\mathrm{N}_{\text {bootstraps }}=10,000\right)$ with ad image and marketing tactics as independent variable (or covariate, respectively), mental simulation, negative mood, and positive mood as parallel mediators, and product valuation as dependent variable. As expected, we found that ad image had a significant indirect effect only via mental simulation $\left(b=.13, S E=.06, \mathrm{CI}_{95}=\right.$ $[.03 ; .26])$ but neither via negative $\operatorname{mood}\left(b=.02, S E=.02, \mathrm{CI}_{95}=[-.01 ; .06]\right)$ nor via positive $\operatorname{mood}\left(b=.03, S E=.06, \mathrm{CI}_{95}=[-.08 ; .14]\right)$. Marketing tactics had no significant indirect effect via negative $\operatorname{mood}\left(b=-.06, S E=.04, \mathrm{CI}_{95}=[-.16 ; .01]\right)$, a significant indirect effect via positive $\operatorname{mood}\left(b=-.14, S E=.06, \mathrm{CI}_{95}=[-.26 ;-.04]\right)$, and, surprisingly, a significant indirect effect via mental simulation $\left(b=-.14, S E=.06, \mathrm{CI}_{95}=[-.27 ;-.04]\right)$. The latter result suggests that using fear appeal marketing tactics can also affect mental simulation. The results did not change when specifying a moderated mediation with the manipulations as predictor and moderator (Process Model $\left.7, N_{\text {bootstraps }}=10,000\right)$. Overall, the findings demonstrate that ads with an image of sunshine increased product valuation only via mental simulation, independent of using a fear (vs. regular) appeal to induce negative mood.

\section{Discussion}

Study 5 improves our understanding in two important ways. First, it provided compelling evidence of the process underlying the effect of weather on product valuation. By orthogonally manipulating factors that primarily influence mental simulation or mood, the study demonstrated that the mental simulation process operates independently of consumers' mood. Second, Study 5 showed another way for practitioners to harness the effects of weather. Instead of relying on 
actual weather or the prospect of weather (per Study 3), managers may use weather images in ads to increase product valuation.

Study 5 used images to manipulate weather. As cloud images may be perceived as less attractive than images of sunshine, we replicated this study using an equally attractive comparison (i.e., a sunset image) and found similar effects (see Web Appendix K). We also replicated this study using a standard manipulation of incidental mood (see Web Appendix L), providing consistent results.

\section{General discussion}

The present work examines how and when weather affects product valuation. Whereas conventional wisdom suggests that product need and mood can explain the effects, we show that weather-related effects are primarily driven by consumers' mental simulation of product use. Our central proposition is that weather increases the valuation of products that are associated with a respective weather state and that are attractive, because weather stimulates mental simulation which in turn drives product valuation. This theorizing was supported through mediation and moderation and by evidence from a large-scale field study and a total of nine experiments across multiple product categories (i.e., shirts, drinking bottles, sunglasses, flowers, sunscreen, and a sample of 100 different product categories sold in online auctions).

\section{Implications for theory}

We elucidate the effects of a ubiquitous environmental factor - weather - on consumer behavior. To date, surprisingly few articles have documented the effects of weather on consumers and even fewer have applied a psychological perspective to examining how weather at the time of the purchase decision may affect that decision (Busse et al. 2015; Buchheim and Kolaska 2016; Murray et al. 2010). We advance this stream of research by providing insights into the underlying 
processes of weather-related effects and by showing that the effects depend on multiple factors. Specifically, our research reveals a novel process account by which weather stimulates mental simulation of product use, which in turn impacts product valuation. By doing so, it also identifies conditions under which weather does and does not affect product valuation. Finally, we show that not all weather states have equal consequences, as the documented mental simulation effects apply primarily to sunshine and snowfall but not to rain.

Notably, our predictions differ substantially from those of prior work. In contrast to a need account (Agnew and Palutikof 1999) and projection bias (Buchheim and Kolaska 2016), a mental simulation account predicts that sunshine only increases product valuation for attractive products but not for unattractive ones. Whereas mood emerged as second mediator in some studies, Study 5 did not confirm this notion despite being particularly designed to disentangle the effects of mental simulation and mood. Moreover, neither the mood nor the need account would predict that weather only affects products that are attractive (per Study 4) or that can be easily mentally simulated (per Study 1). We believe that our theorizing offers not only more precise predictions but also a more comprehensive understanding of the effects of weather on product valuation.

Our findings also contribute to the literature on mental simulation (Escalas 2004; Taylor et al. 1998; Zhao et al. 2011). Previous research has shown that advertisements (Escalas 2004), images (Elder and Krishna 2012), choice formats (Hildebrand et al. 2014), devices (Shen et al. 2016), and even personal traits (Gutsell and Inzlich 2010) can facilitate or impair mental simulation. We add to this body of work by demonstrating that weather can drive consumers' mental simulation. Importantly, weather represents a quite different class of stimuli, namely, environmental cues, which tend to be more subtle but at the same time widely present in consumers' lives. In particular, these cues are inherent to any situation and thus not specific to individuals (like personality traits) or context (Belk 1974). More research is needed to test 
whether such effects can be observed for related environmental cues such as illuminance (de Bellis et al. 2018) and temperature (Zwebner et al. 2013).

\section{Implications for practice}

Firms have started to realize the enormous potential of weather for adjusting their marketing strategies. This work improves the effectiveness of weather-related measures in two ways: by affecting consumer product valuation directly and by generating more precise demand forecasts. Selectively increasing the salience of weather Whereas weather per se cannot be manipulated, firms could selectively display information about current or future weather on their websites and apps to influence consumer behavior. In Study 3, we demonstrated that the prospect of sunshine can affect consumers' response to specific products by showing that weather forecasts can spur consumers' mental simulation and ultimately their valuation of products. Applications such as Google's Gmail or Microsoft's Outlook already have weather forecasts incorporated into their designs. For travel agencies and online booking websites, it has become common practice to inform their customers about the weather in potential destinations (sometimes along with customers' current weather). To increase the likelihood of booking, firms should present this information only when the planned activity relates to the forecasted weather state.

Selectively presenting products Firms that sell products associated with different weather states may more prominently display products on their websites when they match the weather state. Online auction platforms, which constituted the main context of this work, could align the ranking of products in consumer searches with current weather states. For instance, when the sun is shining, products that are associated with sunshine should be ranked higher as consumers are likely to bid a higher price for these products.

Encouraging the use of pictorial information Firms can foster mental simulation of product use by ensuring that their product presentations are accompanied by appropriate pictorial 
information. As demonstrated in Study 5, firms can strategically include pictures of a specific weather state directly in their advertisements for products that are associated with it (e.g., sunshine for sunscreen). Online auction platforms could encourage consumers to upload images of products along with their auctions to facilitate mental simulation, especially for products associated with sunshine and when the sun is shining. Products presented with multiple images should, according to Study 1, be more prone to weather-related effects. This effect could be even more pronounced if the images involve usage situations (Cian, Krishna, and Elder 2015). Firms and auction users should include images of the product use along with the weather in which the product is primarily used.

Dynamically adjusting prices Coca Cola developed vending machines that alter the price of soft drinks based on the ambient temperature (King and Narayandas 2000). It is conceivable that firms could similarly adjust their prices based on weather. Specifically, firms could dynamically adjust the prices of their products depending on whether the products are associated with a given weather state or not. According to our results, consumers should be willing to pay more for products that are associated with a weather state that is currently present. It is important to note, however, that such dynamic pricing may give rise to ethical considerations. If firms exploit the effects revealed by this work and discriminate their prices based on weather, consumers might perceive this as unfair. Policy makers may consider regulating such dynamic pricing mechanisms to restrict weather-related pricing.

\section{Limitations and avenues for future research}

The current work has limitations that provide opportunities for future research. First, we predominantly relied on self-reported measures to assess our mechanisms of mental simulation and did not manipulate mental simulation per se. Similarly, Study 1 only assessed mental simulation by means of the number of product images (conceptualized as exogenous moderator; 
Spencer et al. 2005). Future studies may hold constant the mediator, thus further testing our mental simulation account. Moreover, in our experimental studies, most participants were not directly exposed to weather, which we believe could have further facilitated the effects of mental simulation. Next, the explanatory power of the effects of weather remain small, which is to be expected given that the focal phenomenon is an environmental cue. We also used a precondition of mental simulation (i.e., not overly hot or cold outside temperatures, which would impair mental simulation of product use) as screening criterion. Thus, our predictions only apply to situations where product use is possible. Future work may examine further boundary conditions of mental simulation as predictor of product valuation. Moreover, our studies focused on products and did not include services as stimuli. We believe that the same effects should hold for services—assuming they are strongly associated with a specific weather state—given their experiential, activity-focused nature (Murray 1991) and the high relevance of mental simulation for services (Ülkümen and Thomas 2013). Future research might test whether and how the effects documented for products differ for services. Finally, as we conducted most studies before consumers became increasingly aware of the severe consequences of climate change, the effects of our operationalization of weather (which predominantly relied on sunshine) could become negatively coined in the future. In particular, sunny and warm days could be negatively connotated as people may consider them as an indicator of climate change ( $\mathrm{Li}$, Johnson, and Zaval 2011), with unknown consequences for the documented effects.

Whereas firms have started to realize and leverage the potential of weather, knowledge of the consequences of this group of stimuli is still limited, despite their omnipresence in our everyday lives. This research represents a first step toward advancing this knowledge by revealing the dominant process and specifying the peculiarities and boundaries of weather-related effects on consumers. 


\section{References}

Agnew, M. D. and J. P. Palutikof (1999), “The impacts of climate on retailing in the UK with particular reference to the anomalously hot summer of 1995," International Journal of Climatology, 19(13), 1493-507.

Andrade, E. B. and J. B. Cohen (2007), “On the consumption of negative feelings,” Journal of Consumer Research, 34(3), 283-300.

Belk, R. W. (1974), “An exploratory assessment of situational effects in buyer behavior,” Journal of Marketing Research, 11(2), 156-63.

Buchheim, L. and T. Kolaska (2016), "Weather and the psychology of purchasing outdoor movie tickets," Management Science, 63(11), 3718-38.

Busse, M. R., D. G. Pope, J. C. Pope, and J. Silva-Risso (2015), “The psychological effect of weather on car purchases," Quarterly Journal of Economics, 130(1), 371-414.

Cian, L., A. Krishna, and R. S. Elder (2015), "A sign of things to come: Behavioral change through dynamic iconography," Journal of Consumer Research, 41(6), 1426-46.

Cohen, J., M. Pham, and E. Andrade (2008), “The nature and role of affect in consumer behavior," In C. P. Haugtvedt, P. M. Herr, \& F. R. Kardes (Eds.), Handbook of Consumer Psychology (pp. 297-348). New York: Lawrence Erlbaum Associates.

Cunningham, M. R. (1979), "Weather, mood, and helping behavior: Quasi experiments with the sunshine samaritan," Journal of Personality and Social Psychology, 37(11), 1947-56.

de Bellis, E., M. Schulte-Mecklenbeck, Wernher Brucks, Andreas Herrmann, and Ralph Hertwig (2018), "Blind haste: As light decreases, speeding increases," PLOS ONE, 13(1), e0188951.

Elder, R. S. and A. Krishna (2012), “The 'visual depiction effect' in advertising: Facilitating embodied mental simulation through product orientation," Journal of Consumer Research, 38(6), 988-1003.

Escalas, J. E. (2004), "Imagine yourself in the product: Mental simulation, narrative transportation, and persuasion," Journal of Advertising, 33(2), 37-48.

Fisher, J. D. (1974), "Situation-specific variables as determinants of perceived environmental esthetic quality and perceived crowdedness," Journal of Research in Personality, 8, 177-88.

Gutsell, J. N. and M. Inzlicht (2010), "Empathy constrained: Prejudice predicts reduced mental simulation of actions during observation of outgroups," Journal of Experimental Social Psychology, 46(5), 841-45.

Hayes, A. F. "PROCESS: A versatile computational tool for observed variable mediation, moderation, and conditional process modeling." (2012).

Heyman, J. E., Y. Orhun, and D. Ariely (2004), “Auction fever: The effect of opponents and quasi-endowment on product valuations," Journal of Interactive Marketing, 18(4), 7-21. 
Hildebrand, C., G. Häubl, and A. Herrmann (2014), "Product customization via starting solutions," Journal of Marketing Research, 51(6), 707-25.

Hirshleifer, D. and T. Shumway (2003), "Good day Sunshine: Stock returns and the weather," Journal of Finance, 58(3), 1009-32.

Hong, J. and Y. Sun (2012), "Warm it up with love: The effect of physical coldness on liking of romance movies," Journal of Consumer Research, 39(2), 293-306.

Keller, M. C., B. L. Fredrickson, Oscar Ybarra, Stéphane Côté, Kareem Johnson, Joe Mikels, Anne Conway, and Tor Wager (2005), "A warm heart and a clear head the contingent effects of weather on mood and cognition," Psychological Science, 16(9), 724-31.

Keller, P. A. and A. L. McGill (1994), "Differences in the relative influence of product attributes under alternative processing conditions: Attribute importance versus attribute ease of imagability," Journal of Consumer Psychology, 3(1), 29-49.

King, C. III and D. Narayandas (2000), Coca-Cola's New Vending Machine (a): Pricing to capture value, or not?, 1-9, 9-500-068, https://www.alumni.hbs.edu/Documents/reunions/ Narayandas_AMP\%20Reunion_Coca-Cola\%20Case.pdf.

Lee, J. J., F. Gino, and Bradley R. Staats (2014), "Rainmakers: Why bad weather means good productivity," Journal of Applied Psychology, 99(3), 504-13.

Lehmann, D. R., Jennifer Ames Stuart, Gita V. Johar, and Anil Thozhur (2007), "Spontaneous visualization and concept evaluation," Journal of the Academy of Marketing Science, 35(3), $309-16$.

Li, Y., E. J. Johnson, and L. Zaval (2011), “Local warming,” Psychological Science, 22(4), 45459.

Murray, K. B. (1991), "A test of services marketing theory: Consumer information acquisition activities," Journal of Marketing, 55(1), 10-25.

Murray, K. B., F. Di Muro, A. Finn, and P. Popkowski Leszczyc (2010), "The effect of weather on consumer spending," Journal of Retailing and Consumer Services, 17(6), 512-20.

Nicas, J. (2015), "Now prices can change from minute to minute," Wall Street Journal, accessed November 30, 2016, http://www.wsj.com/articles/now-prices-can-change-from-minute-tominute-1450057990.

Nielsen, J., J. Edson Escalas, and S. Hoeffler (2018), "Mental simulation and category knowledge affect really new product evaluation through transportation," Journal of Experimental Psychology: Applied, 24(3), 145-58.

Petrova, P. K. and R. B. Cialdini (2005), "Fluency of Consumption Imagery and the Backfire Effects of Imagery Appeals," Journal of Consumer Research, 32(3), 442-52.

Pierce, J. L., Tatiana Kostova, and Kurt T. Dirks (2003), "The state of psychological ownership: Integrating and extending a century of research," Review of General Psychology, 7(1), 84107. 
Riccio, D. C., R. Richardson, and D. L. Ebner (1984), "Memory retrieval deficits based upon altered contextual cues: A paradox," Psychological Bulletin, 96(1), 152-65.

Rind, B. (1996), "Effect of beliefs about weather conditions on tipping," Journal of Applied Social Psychology, 26(2), 137-47.

Rind, B. and D. Strohmetz (2001), "Effect of beliefs about future weather conditions on restaurant tipping," Journal of Applied Social Psychology, 31(10), 2160-64.

Sanna, L. J. (2000), "Mental simulation, affect, and personality a conceptual framework," Current Directions in Psychological Science, 7(5), 168-73.

Saunders, E. M. (1993), "Stock prices and wall street weather," American Economic Review, 83(5), 1337-45.

Smith, S. M. and E. Vela (2001), "Environmental context-dependent memory: A review and meta-analysis," Psychonomic Bulletin \& Review, 8(2), 203-20.

Spencer, S. J., M. P. Zanna, and G. T. Fong (2005), "Establishing a causal chain: Why experiments are often more effective than mediational analyses in examining Psychological Processes," Journal of Personality and Social Psychology, 89(6), 845-51.

Taylor, S. E. and S. K. Schneider (1989), "Coping and the simulation of events," Social Cognition, 7(2), 174-94.

Taylor, S. E., L. B. Pham, I. D. Rivkin, and D. A. Armor (1998), "Harnessing the imagination: Mental simulation, self-regulation, and coping," American Psychologist, 53(4), 429-39.

Thompson, D. V., R.W. Hamilton, and P. K. Petrova (2009), "When mental simulation hinders behavior: The effects of process-oriented thinking on decision difficulty and performance," Journal of Consumer Research, 36(4), 562-74.

Ülkümen, G. and M. Thomas (2013), "Personal relevance and mental simulation amplify the duration framing effect," Journal of Marketing Research, 50(2), 194-206.

Watson, D., L. A. Clark, and A. Tellegen (1988), "Development and validation of brief measures of positive and negative affect: The PANAS scales," Journal of Personality and Social Psychology, 54(6), 1063-70.

Zhao, M., S. Hoeffler, and G. Zauberman (2011), "Mental simulation and product evaluation: The affective and cognitive dimensions of process versus outcome simulation," Journal of Marketing Research, 48(5), 827-39.

Zwebner, Y., L. Lee, and J. Goldenberg (2013), “The temperature premium: Warm temperatures increase product valuation," Journal of Consumer Psychology, 24(2), 251-9. 
Fig. 1 Conceptual model of the effect of weather state on consumer product valuation

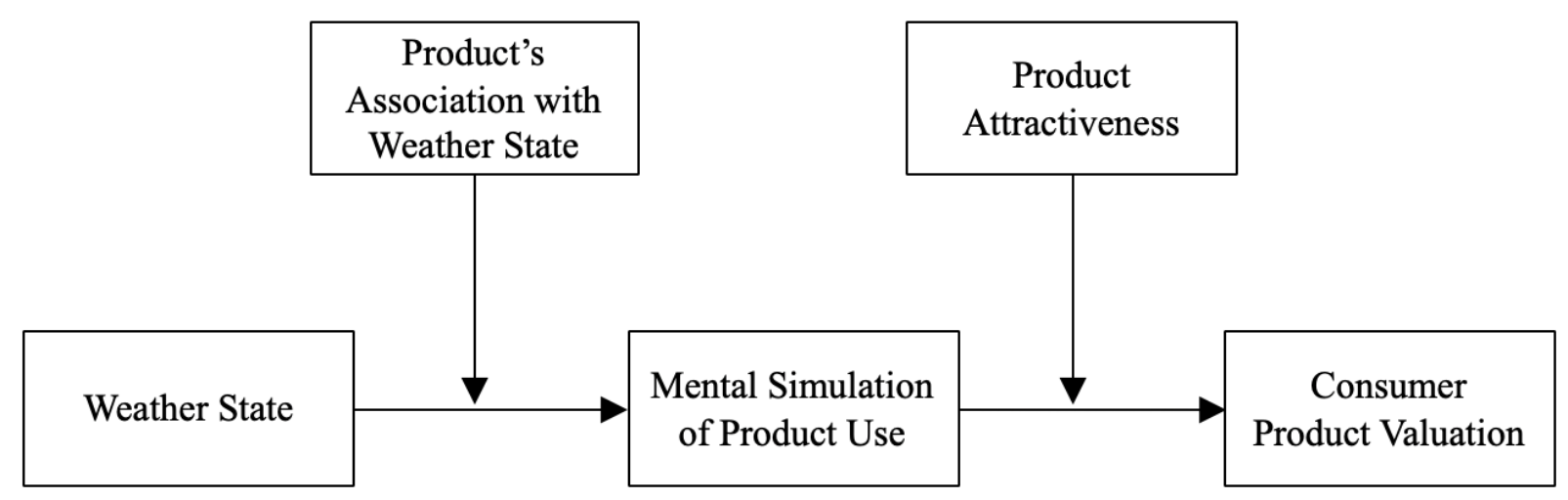


Fig. 2 Sunshine increases the valuation of shirts associated with sunshine (Study 2)

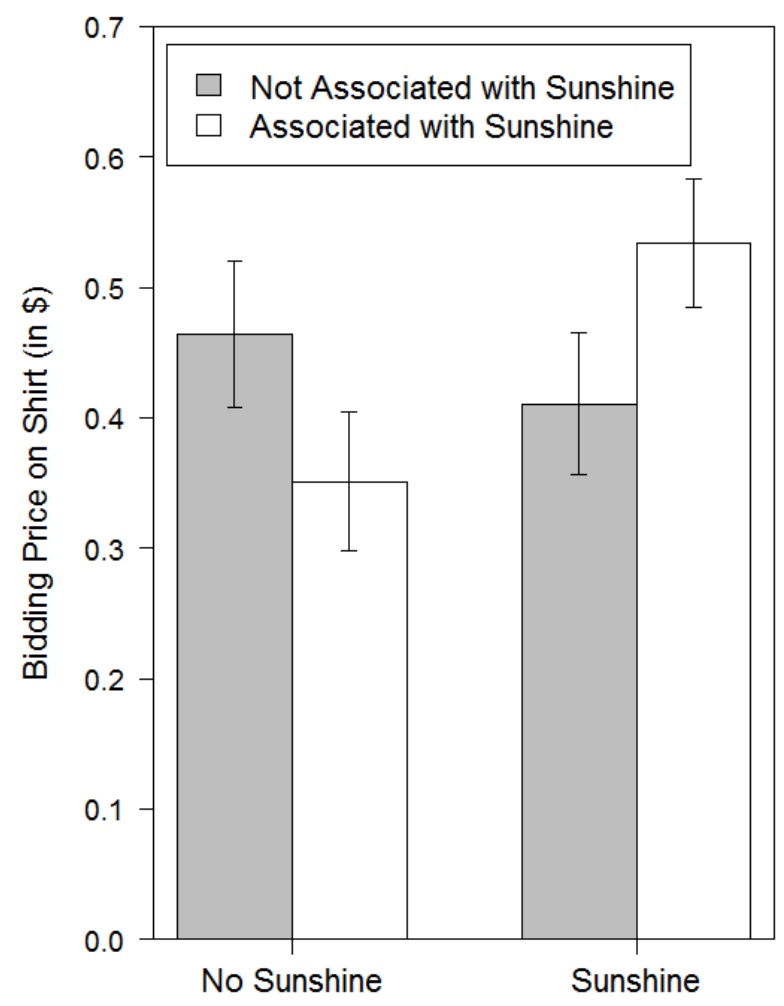


Fig. 3 Product attractiveness moderates the effect of mental simulation on consumer product valuation (Study 4)

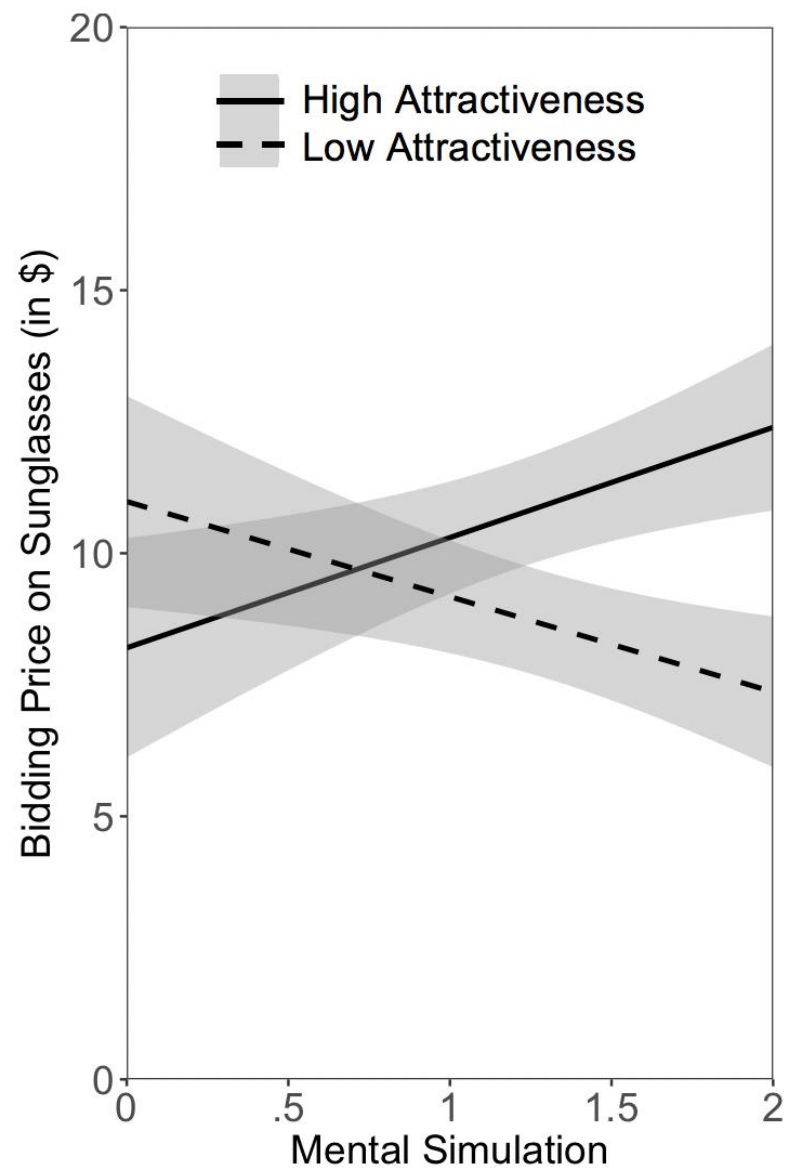

Notes: Shaded areas represent $95 \%$ confidence intervals. 
Table 1 Results of the linear mixed models on consumer product valuation (operationalized by bidding price) (Study 1)

\begin{tabular}{|c|c|c|c|c|c|c|}
\hline & \multicolumn{2}{|r|}{$\begin{array}{l}\text { Model } 1 \\
\text { Baseline }\end{array}$} & \multicolumn{2}{|c|}{$\begin{array}{c}\text { Model } 2 \\
\text { Interaction with match }\end{array}$} & \multicolumn{2}{|c|}{$\begin{array}{c}\text { Model } 3 \\
\text { Interaction with match } \\
\text { and images }\end{array}$} \\
\hline & $b \quad(S E)$ & $t$ & $b \quad(S E)$ & $t$ & $b \quad(S E)$ & $t$ \\
\hline Age [years] & $-.05(.003)$ & $-17.58 * * *$ & $-.05(.003)$ & $-17.51 * * *$ & $-.05(.003)$ & $-17.49 * * *$ \\
\hline Gender [female] & $-.38(.30)$ & -1.26 & $-.39(.30)$ & -1.30 & $-.39(.30)$ & -1.30 \\
\hline Gender [male] & $-.06(.30)$ & -.20 & $-.07(.30)$ & -.24 & $-.07(.30)$ & -.24 \\
\hline Articles sold by seller [number] & $-.12(.001)$ & $-137.67 * * *$ & $-.12(.001)$ & $-137.50 * * *$ & $-.12(.001)$ & $-137.50 * * *$ \\
\hline Article condition [old vs. new] & $.0001(.002)$ & .05 & $.0004(.002)$ & .21 & $.0004(.002)$ & .19 \\
\hline Unique bidders [number] & $.32(.001)$ & $389.43 * * *$ & $.32(.001)$ & $389.65 * * *$ & $.32(.001)$ & $389.60 * * *$ \\
\hline Rain & $-.005(.003)$ & $-1.79+$ & $-.04(.004)$ & $-9.43 * * *$ & $-.04(.004)$ & $-9.54 * * *$ \\
\hline Snow & $-.01(.01)$ & -1.28 & $-.05(.01)$ & $-6.31 * * *$ & $-.05(.01)$ & $-6.27 * * *$ \\
\hline Sun & $.01(.002)$ & $6.02 * * *$ & $-.03(.004)$ & $-9.46 * * *$ & $-.03(.004)$ & $-9.58 * * *$ \\
\hline Images [number] & $.22(.001)$ & $277.33 * * *$ & $.22(.001)$ & $276.72 * * *$ & $.21(.003)$ & $65.73 * * *$ \\
\hline Match [with weather state] & & & $-.04(.004)$ & $-10.51 * * *$ & $-.04(.004)$ & $-10.58 * * *$ \\
\hline Match $\times$ Rain & & & $.23(.03)$ & $6.80 * * *$ & $.19(.04)$ & $4.88 * * *$ \\
\hline Match $\times$ Snow & & & $.08(.02)$ & $3.30 * * *$ & $.07(.02)$ & $2.77 * *$ \\
\hline Match $\times$ Sun & & & $.20(.01)$ & $32.40 * * *$ & $.20(.01)$ & $31.47 * * *$ \\
\hline Images [number] $\times$ Match & & & & & $.01(.003)$ & 1.64 \\
\hline Images [number] $\times$ Rain & & & & & $.01(.004)$ & $3.62 * * *$ \\
\hline Images [number] ×Snow & & & & & $.02(.01)$ & $2.49 *$ \\
\hline Images [number]×Sun & & & & & $-.0002(.003)$ & -.06 \\
\hline Images [number] $\times$ Match $\times$ Rain & & & & & $-.11(.04)$ & $-2.46 *$ \\
\hline Images [number] $\times$ Match $\times$ Snow & & & & & $.08(.02)$ & $3.22 * *$ \\
\hline Images [number] $\times$ Match $\times$ Sun & & & & & $.02(.01)$ & $3.24 * *$ \\
\hline Constant & $3.84(.30)$ & $12.88 \quad * * *$ & $3.88(.30)$ & $13.04 * * *$ & $3.89(.30)$ & $13.04 * * *$ \\
\hline$A I C$ & \multicolumn{2}{|c|}{$9,402,207$} & \multicolumn{2}{|c|}{$9,400,911$} & \multicolumn{2}{|c|}{$9,400,893$} \\
\hline$S D[$ random intercept]Buyer & \multicolumn{2}{|r|}{1.06} & \multicolumn{2}{|r|}{1.06} & \multicolumn{2}{|c|}{1.06} \\
\hline$S D[$ random intercept $]$ Zip code & \multicolumn{2}{|r|}{.05} & \multicolumn{2}{|r|}{.05} & \multicolumn{2}{|c|}{.05} \\
\hline$X^{2} \Delta d f$ against lower model & \multicolumn{2}{|r|}{-} & \multicolumn{2}{|c|}{$1304.58(4) * * *$} & \multicolumn{2}{|c|}{$32.00(7)^{* * *}$} \\
\hline
\end{tabular}

Notes: Additional controls for season $52.7<F<53.4$, weekday $27.9<F<28.1$, daytime $209.6<F<209.8$; 136 customers (approximately .07\%) did not indicate their gender. Continuous variables were mean-centered. $+p<.10, * p<.05, * * p<.01, * * * p<.001$ 
Table 2 Means, standard deviations, and cell sizes of experimental studies

\begin{tabular}{|c|c|c|c|c|c|c|c|c|c|c|}
\hline & & \multicolumn{2}{|c|}{ Consumer product valuation $^{\mathrm{a}}$} & \multicolumn{2}{|c|}{ Mental simulation } & \multicolumn{2}{|c|}{ Positive mood } & \multicolumn{2}{|c|}{ Negative mood } & \multirow[t]{2}{*}{$\mathrm{N}$} \\
\hline & & $M$ & $S D$ & $M$ & $S D$ & $M$ & $S D$ & $M$ & $S D$ & \\
\hline \multirow{4}{*}{$\begin{array}{l}\text { Study 2: } \\
\text { Shirts }\end{array}$} & Sun, association & .53 & .33 & 6.57 & .65 & & & & & 46 \\
\hline & Sun, no association & .41 & .34 & 6.16 & 1.00 & & & & & 40 \\
\hline & No sun, association & .35 & .29 & 6.05 & 1.23 & & & & & 30 \\
\hline & No sun, no association & .46 & .35 & 6.21 & .96 & & & & & 38 \\
\hline \multirow{4}{*}{$\begin{array}{l}\text { Study 3: } \\
\text { Flowers }\end{array}$} & Sun, prospect of sunshine & 27.18 & 18.43 & 6.01 & 1.24 & 2.84 & 1.06 & & & 72 \\
\hline & Sun, no prospect of sunshine & 27.53 & 14.33 & 6.21 & .79 & 3.03 & .85 & & & 70 \\
\hline & No sun, prospect of sunshine & 28.55 & 15.56 & 6.10 & .98 & 3.11 & .73 & & & $31^{\mathrm{b}}$ \\
\hline & No sun, no prospect of sunshine & 19.39 & 13.67 & 5.44 & 1.51 & 2.67 & 1.00 & & & 36 \\
\hline \multirow{4}{*}{$\begin{array}{c}\text { Study 4: } \\
\text { Sunglasses }\end{array}$} & Sun, attractive & 14.13 & 7.13 & 1.29 & .71 & 3.07 & .87 & 1.31 & .60 & 104 \\
\hline & Sun, unattractive & 9.66 & 7.36 & 1.31 & .73 & 2.90 & .96 & 1.40 & .74 & 104 \\
\hline & No sun, attractive & 10.99 & 8.32 & 1.08 & .67 & 2.56 & .99 & 1.45 & .73 & 71 \\
\hline & No sun, unattractive & 9.94 & 7.56 & 1.16 & .77 & 2.76 & 1.03 & 1.52 & .86 & 70 \\
\hline \multirow{4}{*}{$\begin{array}{c}\text { Study 5: } \\
\text { Sunscreen }\end{array}$} & Sunshine, regular appeal & 5.65 & 1.14 & 6.35 & .82 & 2.83 & 1.01 & 1.18 & .49 & 83 \\
\hline & Sunshine, fear appeal & 4.77 & 1.41 & 6.03 & 1.11 & 2.62 & .93 & 1.45 & .72 & 80 \\
\hline & Clouds, regular appeal & 5.34 & 1.31 & 6.05 & 1.27 & 2.82 & .94 & 1.18 & .53 & 80 \\
\hline & Clouds, fear appeal & 4.43 & 1.46 & 5.72 & 1.34 & 2.51 & .88 & 1.64 & .77 & 87 \\
\hline
\end{tabular}

${ }^{a}$ Consumer product valuation was operationalized by bidding price (USD) in studies 2, 3, and 4 and by a self-reported measure in studies 4 and 5 .

${ }^{\mathrm{b}}$ Cell sizes vary according to the prevalence of sunshine in the US on the day the study was conducted. 